\title{
Arabidopsis GOLD36/MVP1/ERMO3 Is Required for Powdery Mildew Penetration Resistance and Proper Targeting of the PEN3 Transporter
}

\author{
William Underwood ${ }^{\dagger}$ \\ United States Department of Agriculture-Agricultural Research Service Sunflower \& Plant Biology Research Unit, \\ Edward T. Schafer Agricultural Research Center, Fargo, ND 58102, U.S.A.
}

Accepted 9 February 2022.

\begin{abstract}
The Arabidopsis PENETRATION 3 (PEN3) ATP binding cassette (ABC) transporter contributes to penetration resistance against nonadapted powdery mildew fungi and is targeted to papillae deposited at sites of interaction with the fungus. Timely recruitment of PEN3 and other components of penetration resistance to the host-pathogen interface is important for successful defense against this biotrophic pathogen. A forward genetic screen was previously carried out to identify Arabidopsis mutants that mistarget the PEN3 transporter or fail to accumulate PEN3 at sites of attempted powdery mildew penetration. This study focuses on PEN3 mistargeting in the aberrant localization of PEN3 4 (alp4) mutant and identification of the causal gene. In the alp4 mutant, PEN3 accumulates within the endomembrane system in an apparently abnormal endoplasmic reticulum and is not exported into papillae at powdery mildew penetration sites. This targeting defect compromises defenses at the host-pathogen interface, resulting in increased penetration success by a nonadapted powdery mildew. Genetic mapping identified alp 4 as an allele of GOLGI DEFECTS 36 (GOLD36), a gene encoding a GDSLlipase/esterase family protein that is involved in maintaining normal morphology and organization of multiple endomembrane compartments. Genetic complementation confirmed that mutation in GOLD36 is responsible for the PEN3 targeting and powdery mildew penetration resistance defects in alp4. These results reinforce the importance of endomembrane trafficking in resistance to haustorium-forming phytopathogens such as powdery mildew fungi.
\end{abstract}

Keywords: disease resistance, endomembrane trafficking, fungus-plant interactions, microscopy and imaging, non-host resistance, papilla,

${ }^{\dagger}$ Corresponding author: W. Underwood; william.underwood@usda.gov

The United States Department of Agriculture is an equal opportunity provider and employer.

Funding: This research was funded, in part, by National Institute of Health (NIH) Postdoctoral Fellowship F32-GM-0834393 and by funding from the United States Department of Agriculture-Agricultural Research Service to W. Underwood, CRIS Project 3060-21220-031-00D. This project utilized the University of California-Berkeley Vincent J. Coates Genomics Sequencing Laboratory, funded by NIH S10 Instrumentation Grants S10RR029668 and S10RR027303.

The author declares no conflict of interest.

(c) (1) ()$\odot$ Copyright $\odot 2022$ The Author(s). This is an open access article distributed under the CC BY-NC-ND 4.0 International license. plant antifungal responses, plant disease, plant responses to pathogens, secretion and cell wall changes

Powdery mildew fungi are among the most common causal agents of plant disease, affecting a wide array of angiosperm plants (Glawe 2008). Powdery mildew species are obligate parasites that acquire nutrients from their hosts through formation of haustoria, specialized infection structures in close contact with the plasma membrane (PM) of host cells. Successful formation of haustoria requires breach of the plant cell wall by fungal appressoria through a combination of physical pressure and enzymatic degradation. During interactions between nonhost plants and nonadapted powdery mildew species, the attacked plant cell responds to attempted cell wall penetration with a local cell wall reinforcement known as a papilla. Most powdery mildew species form haustoria only in plant epidermal cells and proliferate on the leaf surface (Barnes 1979). This accessibility to the infection process has allowed powdery mildew-plant interactions to be used as models to study the physical and cellular processes associated with defense responses leading to cell wall modification and reinforcement.

Several forward genetic screens have identified molecular components contributing to penetration defense against powdery mildew attack. Screens to identify Arabidopsis thaliana mutants that allowed the nonadapted barley powdery mildew Blumeria graminis f. sp. hordei to establish haustoria at a higher frequency than the wild type yielded a number of penetration (pen) mutants. Genetic mapping and cloning identified PENETRATION 1 (PEN1) as a PM-resident soluble N-ethylmaleimide sensitive factor attachment protein receptor (SNARE) protein mediating vesicle fusion events (Assaad et al. 2004; Collins et al. 2003). PEN2 was determined to be an atypical myrosinase localized to peroxisomes and mitochondria and involved in the biosynthesis of an indole glucosinolate-derived secondary metabolite contributing to antifungal defense (Bednarek et al. 2009; Clay et al. 2009; Fuchs et al. 2016; Lipka et al. 2005). Cloning of PEN3 revealed a PM-localized ATP-binding cassette (ABC) transporter required for full penetration resistance and proposed to transport the PEN2-derived defensive metabolite (Stein et al. 2006). PEN3 has subsequently been proposed to transport the indole derivative 4-methoxyindole-3-methanol as well as the phytoalexin camalexin (He et al. 2019; Matern et al. 2019). PEN4 was identified as the PCS1 phytochelatin synthase and found to function in the same defensive metabolic pathway as PEN2 and to colocalize with PEN2 on immobilized mitochondria (Hématy et al. 2020). Both PEN1 and PEN3 exhibit strong focal accumulation at sites of attempted cell wall penetration by nonadapted powdery mildew 
species such as B. graminis f. sp. hordei and both proteins have been shown to accumulate outside the cell, on membrane materials present within the cell-wall-reinforcing papilla structure (Meyer et al. 2009; Underwood and Somerville 2013). Further experimental work demonstrated that PEN1 and PEN3 follow distinct trafficking routes to papillae and identified the transgolgi network (TGN)-localized lipid flippase aminophospholipid ATPase 3 (ALA3) as an endomembrane trafficking regulator affecting the timing of recruitment of PEN1 and PEN3 to sites of powdery mildew attack (Underwood and Somerville 2013; Underwood et al. 2017). In addition to the products of the PEN genes, enhanced disease resistance 4 accumulates at powdery mildew penetration sites and negatively affects defense (Wu et al. 2015). The actin-associated FORMIN4 has also been shown to accumulate at sites of pathogen attack through trafficking pathways that appear distinct from those taken by PEN3 and in apparently distinct cell surface subdomains (Sassmann et al. 2018). Additionally, the powdery-mildew-resistant 4 (PMR4) callose synthase also accumulates at penetration sites and is required for deposition of callose in papillae (Ellinger et al. 2013; Jacobs et al. 2003; Nishimura et al. 2003).

Regulation and reorientation of endomembrane trafficking and vesicle-mediated secretion play additional crucial roles in plant immune responses beyond the deposition of localized cell wall reinforcements at sites of pathogen attack. Pattern recognition receptors such as flagellin sensing 2 (FLS2) that detect the presence of a pathogen and initiate plant pattern-triggered immunity are constitutively endocytosed and cycled back to the PM in the absence of pathogen detection but undergo ligand-induced endocytosis and degradation upon recognition of pathogen signals (Beck et al. 2012; Mbengue et al. 2016; Ortiz-Morea et al. 2016). Additionally, the abundance of FLS2 in the PM is affected by the clathrin adapter EPSIN1 involved in vesicle trafficking from the TGN to the PM (Collins et al. 2020). There is also increasing interest in the roles of plant extracellular vesicles in defense responses and interactions with pathogenic microorganisms, including a potential role for these structures in crosskingdom RNA silencing during plant-microbe interactions (Cai et al. 2018; Rutter and Innes 2017, 2018). Given the importance of and numerous roles for plant endomembrane trafficking in antimicrobial defense, it is not surprising that pathogen effectors appear to commonly target components of the plant endomembrane trafficking system (Du et al. 2015; Hossain et al. 2021; Lee et al. 2012; Nomura et al. 2011).

A confocal microscopy-based forward genetic screen was previously carried out to identify Arabidopsis mutants that mistarget the PEN3 ABC transporter (Underwood et al. 2017). In total, 20 mutants were isolated exhibiting a variety of PEN3 localization defects and, in many cases, altered penetration defense against $B$. graminis f. sp. hordei. Previous characterization of the aberrant localization of PEN3 3 (alp3) mutant uncovered a role for the ALA3 lipid flippase in PEN3 trafficking and revealed the importance of reorientation of TGN-PM cycling in delivery of PEN3 and PEN1 to sites of powdery mildew attack (Underwood et al. 2017). This article describes characterization of the PEN3 localization and powdery mildew defense defects in the alp4 mutant as well as identification of the underlying gene. These results identify a new endomembrane trafficking component affecting transport of a defense-related protein through the plant endomembrane system.

\section{RESULTS}

\section{PEN3 targeting and powdery mildew penetration} resistance defects in the alp4 mutant.

The alp4 mutant was previously identified in a forward genetic screen for mutants that mislocalize a green fluorescent protein
(GFP) fusion to the PEN3 ABC transporter after inoculation with the nonadapted powdery mildew fungus $B$. graminis $\mathrm{f}$. sp. hordei (Underwood et al. 2017). The PEN3-GFP fusion protein is normally localized at the PM in uninoculated plants and is subsequently recruited to sites of attempted powdery mildew penetration, where it exhibits focal accumulation and is exported out of the cell into cell wall reinforcements referred to as papillae (Stein et al. 2006; Underwood and Somerville 2013) (Fig. 1A and B). In the alp4 mutant, PEN3-GFP appears to accumulate in an endomembrane compartment, potentially the endoplasmic reticulum (ER), in the absence of powdery mildew attack (Fig. 1A and B). Upon inoculation of alp4 with B. graminis f. sp. hordei, PEN3-GFP remains detectable in the endomembrane compartment and some focal accumulation at sites of attempted penetration by fungal appressoria is observed (Fig. 1A). However, PEN3-GFP does not appear to localize within the interior of papillae in alp4, in contrast to localization observed in the PEN3-GFP parent line (Fig. 1A). To determine whether mistargeting of PEN3-GFP in the alp4 mutant alters penetration resistance against $B$. graminis f. sp. hordei, penetration success and haustorium formation by $B$. graminis $\mathrm{f}$. $\mathrm{sp}$. hordei were evaluated in alp4 in comparison with wild-type Col-0, the PEN3-GFP parent line (Col-0 genetic background), and the pen3-3 (SALK_110926) mutant lacking the PEN3 transporter and impaired in powdery mildew penetration resistance. The alp 4 mutant allowed B. graminis f. sp. hordei to penetrate the cell wall and establish haustoria significantly more frequently than Col-0 or PEN3-GFP and was not significantly different from the pen3-3 mutant (Fig. 1C). Although PEN3-GFP focal accumulation at sites of papilla deposition was disrupted in the alp4 mutant, apparently normal callose deposition was observed in papillae and haustorial encasements (Fig. 1D).

PEN3 export into papillae is impaired in the alp4 mutant.

PEN3 recruitment to sites of attempted powdery mildew penetration is typically accompanied by accumulation of the transporter outside the cell, within the interior of the cell wall reinforcing papillae (Underwood and Somerville 2013). In the alp4 mutant, accumulation of PEN3-GFP in the center of papillae was not typically observed at powdery mildew penetration sites (Fig. 1A). To determine whether extracellular accumulation of PEN3-GFP within papillae is blocked or reduced in the alp4 mutant, plasmolysis experiments were performed to observe and quantify extracellular PEN3-GFP accumulation at penetration sites. In the PEN3-GFP parent line, the PEN3-GFP signal persisted within papillae at penetration sites outside of the retracted protoplast upon plasmolysis (Fig. 2A). In contrast, no PEN3-GFP signal was observed at most penetration sites after plasmolysis of the alp4 mutant (Fig. 2A). To quantify the impairment of PEN3 extracellular accumulation in the alp4 mutant, the frequency of PEN3-GFP accumulation was determined at 10 penetration sites after plasmolysis for the alp4 mutant, the PEN3-GFP parent line, and another alp mutant, alp3. The alp3 mutant is disrupted in the $A L A 3$ gene encoding a lipid flippase and exhibits delayed recruitment of PEN3 to penetration sites but is not impaired in PEN3 extracellular accumulation (Underwood et al. 2017). At $24 \mathrm{~h}$ postinoculation (hpi) with B. graminis f. sp. hordei, PEN3GFP accumulated extracellularly, within papillae, at all observed penetration sites in the PEN3-GFP parent line and the alp3 mutant (Fig. 2B). In contrast, extracellular accumulation of PEN3-GFP within papillae was strongly and significantly reduced in the alp4 mutant (Fig. 2B).

\section{Genetic mapping and identification of alp4.}

To map the mutation responsible for the alp4 phenotype, Illumina sequencing was performed on bulked $F_{2}$ segregants 
exhibiting the alp 4 phenotype from a cross between alp 4 and Landsberg erecta (Ler). Using the next-generation mapping procedure (Austin et al. 2011), a region on the right arm of chromosome 1 was identified exhibiting a low frequency of polymorphism and high "discordant chastity" values for polymorphisms present in the region (Fig. 3). To identify candidate genes for alp4, genes within the mapped region on chromosome 1 possessing G/C to $\mathrm{A} / \mathrm{T}$ transition polymorphisms with discordant chastity values greater than 0.9 were considered. This resulted in identification of seven candidate genes (Table 1). Among the seven candidates, At1g54030, known as GOLGI

A

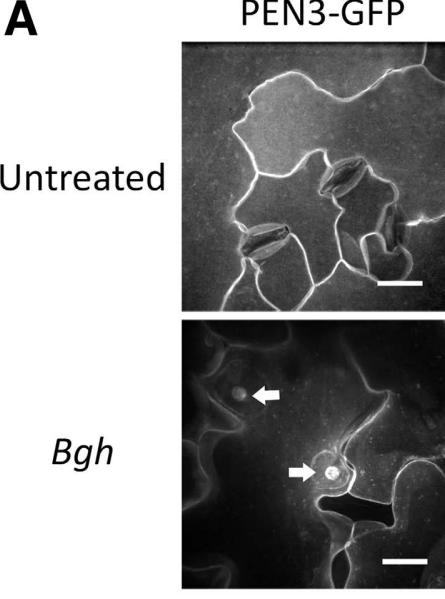

B

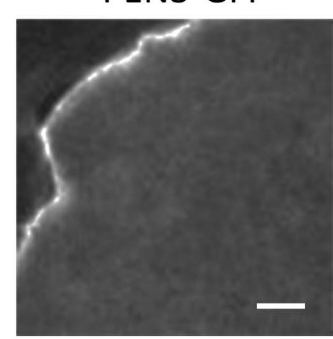

C
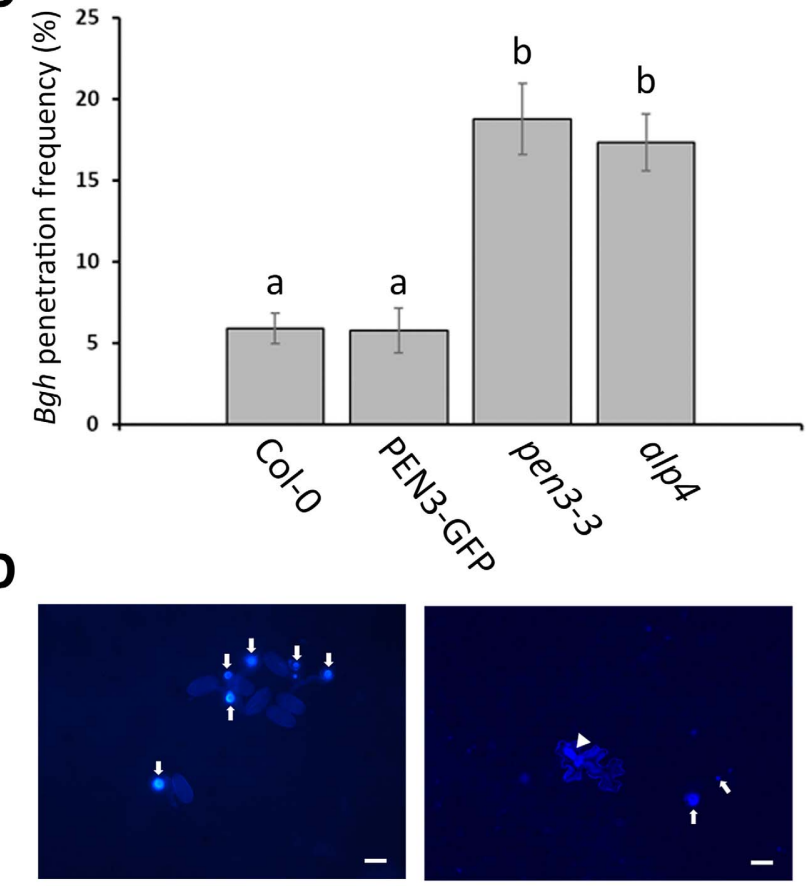

PEN3-GFP
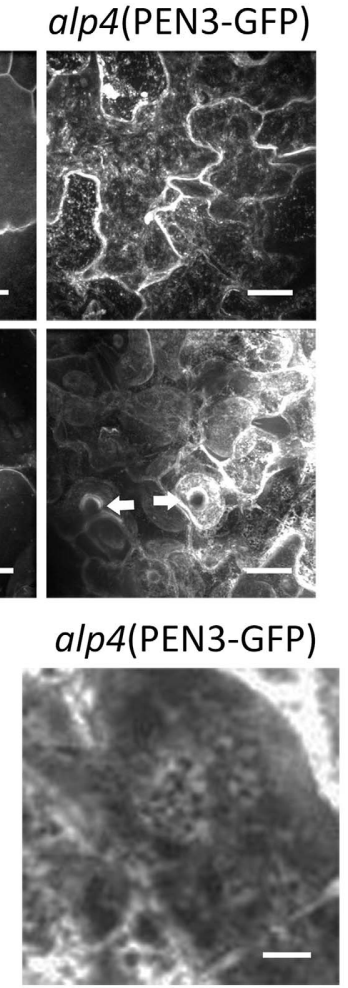

b

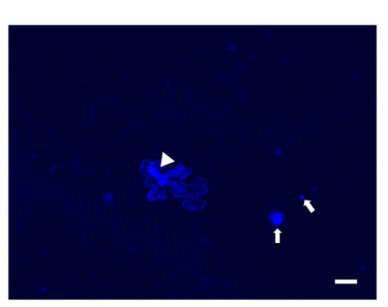

alp4
DEFECTS 36 (GOLD36), MODIFIED VACUOLE PHENOTYPE 1 (MVP1), ENDOPLASMIC RETICULUM MORPHOL$O G Y 3$ (ERMO3), and NUCLEAR CAGE (NUC), has previously been identified in multiple screens for mutants exhibiting defects in endomembrane trafficking and organization (Agee et al. 2010; Jancowski et al. 2014; Marti et al. 2010; Nakano et al. 2012). Mutants in this gene exhibit numerous endomembrane organization defects, including abnormal ER morphology and aberrant protein trafficking through the endomembrane system. Given that PEN3-GFP appears to accumulate in an abnormal ER-like structure, At1g54030 (hereafter, GOLD36) was a likely candidate for the gene underlying the alp4 defects. In the alp4 mutant, GOLD36 exhibits a missense mutation, resulting in substitution of alanine at amino acid position 231 to threonine (Fig. 4A). Two transferred DNA (T-DNA) insertional mutants, mvp1-2 (SALK_030621) and ermo3-2 (SALK_135215), were acquired to determine whether mutation in GOLD36 causes the defect in powdery mildew penetration resistance observed for alp4 (Agee et al. 2010; Nakano et al. 2012). Both the mvpl-2 and ermo3-2 mutants were significantly more susceptible to $B$. graminis f. sp. hordei penetration than Col-0 or PEN3-GFP and were not significantly different from alp4 and pen3-3 (Fig. 4B), indicating that mutation in GOLD36 impairs powdery mildew penetration resistance.

Transgenic expression of GOLD36-monomeric red fluorescent protein complements PEN3-GFP localization and powdery mildew penetration resistance defects in alp4.

To further confirm the identification of GOLD36 as the gene affecting the PEN3 localization and powdery mildew penetration phenotypes observed in the alp4 mutant, complementation of alp4 was attempted by transgenic expression of a GOLD36monomeric red fluorescent protein (mRFP) fusion from the CaMV 35S promoter. Transformation of alp4 with GOLD36mRFP restored normal PEN3-GFP localization at the PM (Fig. 5A). Additionally, transgenic expression of GOLD36mRFP in alp 4 complemented the powdery mildew penetration resistance defect, restoring penetration defense to levels statistically similar to those of Col-0 and PEN3-GFP (Fig. 5B). Taken together, these results confirm that mutation in GOLD36 causes the phenotypes observed in the alp 4 mutant and indicate that

Fig. 1. PENETRATION 3 (PEN3)-green fluorescent protein (GFP) mislocalization and powdery mildew penetration defense defects in the aberrant localization of PEN3 4 (alp4) mutant. A, Confocal micrographs of PEN3-GFP localization in epidermal cells of the PEN3-GFP parental line (left panels) or the alp4 mutant (right panels) in either untreated (upper panels) or Blumeria graminis f. sp. hordei (Bgh)-inoculated (lower panels) leaves. Arrows indicate sites of attempted B. graminis f. sp. hordei penetration. B, Higher-magnification confocal micrographs illustrating PEN3-GFP localization in epidermal cells of the alp4 mutant (left panel) or the PEN3-GFP parental line (right panel) in untreated leaves. C, B. graminis f. sp. hordei penetration frequencies on the Col-0 ecotype (background for PEN3-GFP), the PEN3-GFP parental line, the pen3-3 mutant, and the alp4 mutant. Penetration frequencies were determined by visually scoring for presence or absence of haustoria at 100 infection sites per leaf for three leaves per plant line at $48 \mathrm{~h}$ postinoculation (hpi). Mean values are plotted, and error bars indicate standard deviation $(n=3)$. Means indicated by the same letter are not significantly different according to analysis of variance followed by Tukey's post hoc test $(P<0.05)$. D, Micrographs of aniline-blue-stained leaf tissue showing callose accumulation in papillae at sites of attempted B. graminis f. sp. hordei penetration in the PEN3-GFP parental line (left panel) or in papillae and a haustorial encasement in the alp4 mutant (right panel). Images were collected at $48 \mathrm{hpi}$. Arrows indicate callose papillae and arrowhead indicates a haustorial encasement. Scale bars: $20 \mu \mathrm{m}$ (A and D) and $4 \mu \mathrm{m}(\mathrm{B})$. 
GOLD36 is essential for normal trafficking and localization of the PEN3 transporter and full penetration resistance against a nonadapted powdery mildew fungus.

\section{DISCUSSION}

Plant cells mount a multifaceted defense response upon detection of pathogen cues. One aspect of antimicrobial defenses initiated when plant cells perceive attack by a pathogen is the targeted deposition of physical and chemical barriers at the site of pathogen detection (Bhandari and Brandizzi 2020; Underwood and Somerville 2008). Targeting of defenses to the host-pathogen interface involves reorientation of endomembrane trafficking to rapidly deliver proteins, structural compounds, and defensive metabolites to the site of pathogen detection. Consequently, understanding the endomembrane trafficking pathways that contribute to local defenses at the host-pathogen interface and the regulatory mechanisms that control the targeting and timing of these trafficking pathways will help to clarify the outputs of plant defense activation and aid in understanding how successful pathogens overcome or circumvent defense responses.

The PM-localized Arabidopsis PEN3 ABC transporter is recruited to sites of attempted cell wall penetration by the nonadapted powdery mildew $B$. graminis $\mathrm{f}$. sp. hordei and is a useful marker for one of multiple endomembrane trafficking pathways contributing to the localized defense response against this pathogen (Stein et al. 2006; Underwood et al. 2017). To gain insights into the pathways and processes involved in subcellular trafficking of PEN3, a forward genetic screen was previously carried out to identify Arabidopsis mutants exhibiting aberrant localization of PEN3-GFP after inoculation with $B$. graminis $\mathrm{f}$. sp. hordei. This screen yielded 20 mutants that were grouped into four categories based on the nature of PEN3-GFP mislocalization, and 8 of these mutants exhibited altered penetration resistance against $B$. graminis f. sp. hordei, indicating that the trafficking defects compromised defense against this pathogen. Characterization of the alp3 mutant identified in this screen and impaired in a TGN-localized lipid flippase revealed that PEN3 is continuously cycled through the TGN and redirected to sites of pathogen detection, reinforcing the notion that the TGN is a critical sorting platform for plant antimicrobial defense responses. This study reports characterization of the PEN3 localization and powdery mildew defense defects in the alp4 mutant and identification of the underlying gene.

The alp4 mutant exhibited PEN3-GFP localization in an unknown endomembrane compartment, with some apparent aggregates and puncta and some web-like structures similar in appearance to the ER. Mistargeting of PEN3-GFP was observed in both the presence and absence of powdery mildew inoculation, indicating a constitutive trafficking defect, and the mutant was impaired in penetration resistance against B. graminis $\mathrm{f}$. sp. hordei. Mapping and genetic complementation identified the alp4 mutation as an allele of the previously characterized MVP1/GOLD36/ERMO3/NUC gene. Mutants in this gene have been identified in several similar, microscopy-based genetic screens for mislocalization of membrane marker proteins targeted to different cellular membranes (Agee et al. 2010; Jancowski et al. 2014; Marti et al. 2010; Nakano et al. 2012). Agee and colleagues (2010) initially identified a mutant affected in this gene, $m v p l$, in a microscopy-based screen for mutants that mislocalized a GFP- $\delta$ tonoplast intrinsic protein $(\delta$-TIP) fusion that is normally targeted to the vacuolar membrane. These authors also found that mvpl mislocalized the ER marker YFP-SEC12, the golgi marker NAG1-GFP, the PM marker GFP-PIP2a, and an additional tonoplast marker (GFP- $\gamma$-TIP-like), indicating broad defects in trafficking of proteins destined to multiple cellular membranes. Subsequently, the mutant gold36, identified in a screen for mislocalization of the golgi marker ST-GFP, was also found to be disrupted in the same gene (Marti et al. 2010). The gold36 mutant was also found to mistarget secRFP, a fluorescent reporter normally secreted to the apoplast, adding secretory protein cargo to the list of proteins mislocalized in mutants disrupted in this gene (Marti et al. 2010). Additionally, Marti and colleagues (2010) used marker colocalization to confirm that the mistargeted Golgi and secretory marker proteins were retained in an abnormal-appearing ER. Two additional screens, one for ER morphology defects using an ER-targeted fluorescent marker and one for aberrant localization of GDSL-like lipase GLL23, both identified mutants in GOLD36 conferring defects in ER morphology and protein targeting (Jancowski et al. 2014; Nakano et al. 2012). Collectively, these prior studies and the work reported here are consistent with significant defects in ER organization and protein export that affect trafficking to most or all post-ER cargo destinations. Given these prior results and the ER-like appearance of the PEN3-GFP signal in the alp4 mutant,
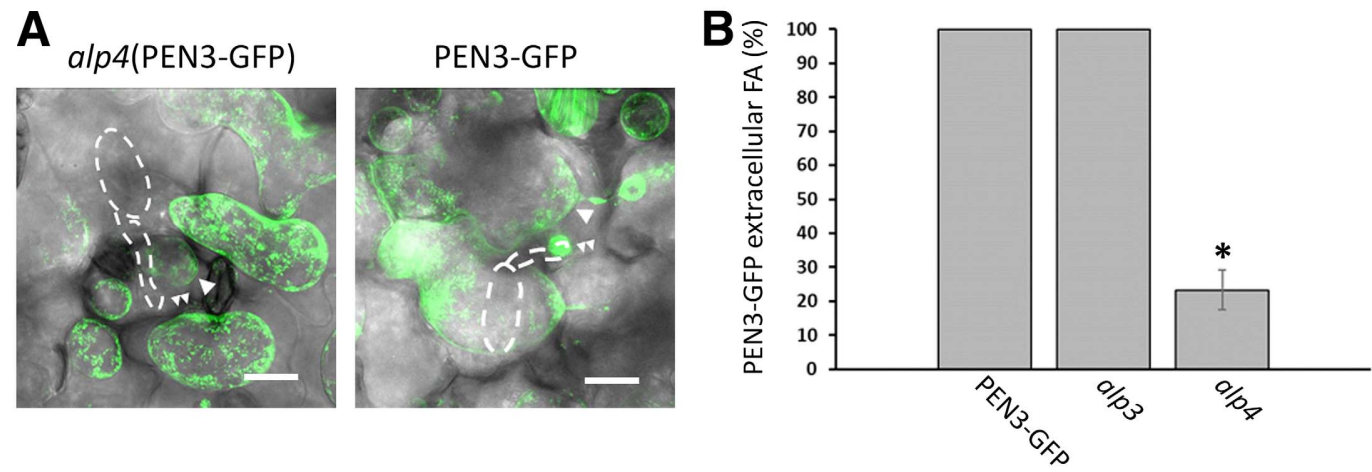

Fig. 2. Extracellular accumulation of PENETRATION 3 (PEN3)-green fluorescent protein (GFP) at Blumeria graminis f. sp. hordei penetration sites is impaired in the aberrant localization of PEN3 4 (alp4) mutant. A, Extracellular accumulation of PEN3-GFP at B. graminis f. sp. hordei penetration sites in the alp4 mutant (left panel) or the PEN3-GFP parental line (right panel) after plasmolysis in $0.85 \mathrm{M} \mathrm{NaCl}$. Images were collected at $24 \mathrm{~h}$ postinoculation (hpi). The PEN3-GFP signal from a z-projected confocal micrograph is displayed in green and overlaid onto the corresponding bright-field image. Double arrowheads indicate the epidermal cell wall boundary and single arrowheads indicate the PEN3-GFP signal at the plasma membrane of the retracted protoplast. The dashed white line indicates the outline of the B. graminis f. sp. hordei conidiospore and appressorial germ tube. Scale bars represent $20 \mu \mathrm{m}$. B, Frequencies of PEN3-GFP extracellular focal accumulation (FA) observed at tips of $B$. graminis f. sp. hordei haustoria in plasmolyzed samples at 24 hpi for the PEN3-GFP parental line, the alp3 mutant, and the alp4 mutant. Accumulation of PEN3-GFP was scored at the tips of 25 B. graminis f. sp. hordei appressoria per leaf for three leaves of each line. Error bars represent standard deviation and asterisk indicates a significant difference compared with the PEN3-GFP parental line $(P<0.01$; Student's $t$ test $)$. 
it is likely that PEN3-GFP is retained in the ER in alp4 due to defects in ER export. The GOLD36 protein was initially localized to the ER, ER bodies, and the tonoplast using a GFP fusion (Agee et al. 2010). However, subsequent results with RFP fusions more tolerant to low $\mathrm{pH}$ suggested that GOLD36 is delivered to the vacuolar lumen (Marti et al. 2010; Nakano et al. 2012). Although GOLD36 is proposed to function in protein export from the ER and the maintenance of proper ER morphology, the mechanisms through which this protein affect subcellular trafficking and endomembrane organization remain unclear. Although GOLD36 is a member of the GDSL-lipase/esterase protein family, the protein was previously found to possess no lipase or esterase activity in vitro, and mutation of a putative catalytic site did not disrupt GOLD36 function in promoting normal ER organization (Agee et al. 2010; Nakano et al. 2012). Based on interaction of GOLD36 with components of the PYK10 complex, involved in glucosinolate hydrolysis, GOLD36 has previously been proposed to affect ER morphology by regulating formation of the PYK10 complex (Jancowski et al. 2014; Nakano et al. 2012). Further functional studies will be required to determine the exact role of GOLD36 in promoting normal ER morphology and endomembrane organization.

At least two distinct subcellular trafficking pathways contribute to localized recruitment of defenses at sites of papilla deposition (Underwood and Somerville 2013). PEN3 and PEN1 are trafficked to the host-pathogen interface through at least partially distinct pathways (Underwood and Somerville 2013; Underwood et al. 2017). Whether mutation in GOLD36 affects

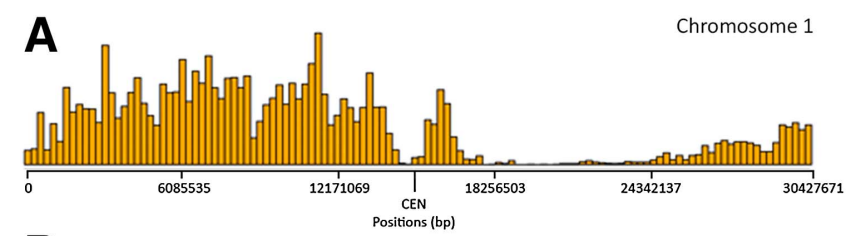

B

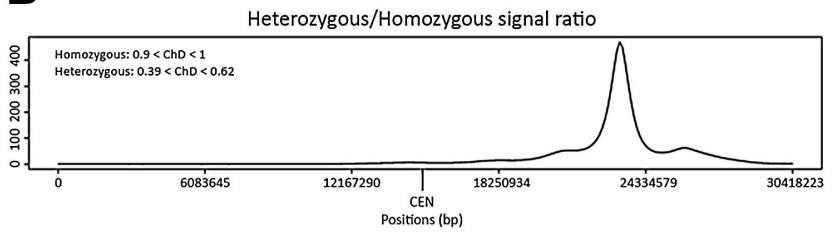

Fig. 3. Genetic mapping delineates the aberrant localization of PEN3 4 (alp4) mutation to a region on chromosome 1. A, Single-nucleotide polymorphism frequencies showing a "single-nucleotide polymorphism desert" with low frequencies of Landsberg erecta alleles in the region between positions $1,825,603$ and $24,342,137$ on chromosome 1 due to linkage with the alp 4 mutation. B, Discordant chastity values showing the predicted peak region for the alp 4 mutation on chromosome 1 . $\mathrm{CEN}=$ centromere in both panels. trafficking of other defense-related proteins to sites of attempted powdery mildew penetration will be interesting to determine. Notably, the defect in powdery mildew penetration resistance in the alp4 mutant is similar in magnitude to the pen3-3 mutant, whereas double mutants impaired in both PEN1 and PEN3 exhibit additive effects on mildew penetration frequencies. This would seem to suggest that alp4 may be affected only in trafficking of PEN3. However, partial effects of the mutation on trafficking of multiple defense proteins resulting in a penetration defect of a similar magnitude to that of the pen3-3 single mutant cannot be ruled out. Nonetheless, delivery of the PMR4 callose synthase responsible for callose deposition within papillae did not appear to be substantially disrupted in the alp4 mutant, because apparently normal callose deposition was observed in papillae at sites of attempted penetration and in encasements around haustoria at sites of successful penetration. Additional research will be required to determine whether GOLD36 defines a trafficking route that includes PEN3 but not other defenserelated protein cargo such as PEN1 or PMR4, or whether mutation in GOLD36 causes partial defects in trafficking of multiple defense cargoes.

Interestingly, another Arabidopsis mutant exhibiting PEN3GFP accumulation in the ER was also identified by a similar microscopy-based screen for PEN3-GFP mislocalization in root tissues (Mao et al. 2017). Mapping revealed a mutation in At3g09030, encoding a protein containing a BTB/POZ domain, responsible for ER retention of PEN3-GFP in this mutant. In contrast to gold36 mutants, the er-arrested pen3-1 (eap3-1) mutant identified in this screen did not exhibit mislocalization of other membrane markers, suggesting a more specific effect on PEN3 trafficking. Mao and colleagues (2017) reported increased susceptibility of eap3-1 to the root-infecting fungal pathogen Fusarium oxysporum f. sp. conglutinans that was similar to increased susceptibility observed for the pen3-4 mutant. The mvp 1-1 mutant was previously determined to exhibit increased susceptibility to the fungal pathogen Alternaria brassicicola (Agee et al. 2010), though whether increased susceptibility to this fungus is due primarily to mislocalization of PEN3 or also affected by mislocalization of other defense-related proteins or compounds in this mutant remains to be determined.

In conclusion, this study identified a new component affecting subcellular trafficking of the PEN3 transporter, its delivery to sites of pathogen attack, and penetration resistance against a nonadapted powdery mildew fungus. It will be interesting to determine whether other targeted defense proteins and cargoes are also mislocalized in gold36 mutants and the extent to which aberrant and disordered secretory trafficking in this mutant affects defense against other pathogens. This mutant may prove useful in defining specific trafficking pathways and processes contributing to delivery of distinct defense cargoes to sites of pathogen attack.

Table 1. Candidate Arabidopsis genes on chromosome 1 possessing $\mathrm{G} / \mathrm{C}$ to $\mathrm{A} / \mathrm{T}$ single-nucleotide polymorphisms with discordant chastity (SNP DC) values $>0.9^{\mathrm{a}}$

\begin{tabular}{|c|c|c|c|}
\hline Gene ID & SNP DC & Gene names & Description \\
\hline Atlg53935 & 1 & N/A & Hypothetical protein \\
\hline At1g63340 & 0.99 & N/A & Flavin-containing monooxygenase family protein \\
\hline Atlg51860 & 0.98 & N/A & Leucine-rich repeat protein kinase family protein \\
\hline At1g50270 & 0.96 & N/A & Pentatricopeptide repeat superfamily protein \\
\hline Atlg61080 & 0.95 & N/A & Hydroxyproline-rich glycoprotein family protein \\
\hline At1g54030 & 0.93 & $\begin{array}{l}\text { GOLD36, modified vacuole phenotype } 1 \\
\text { (MVP1), endoplasmic reticulum } \\
\text { morphology } 3 \text { (ERMO3), nuclear cage } \\
(\text { NUC) }\end{array}$ & $\begin{array}{l}\text { Encodes a vacuolar protein; mutation causes } \\
\text { organizational defects in the endoplasmic } \\
\text { reticulum and aberrant protein trafficking in } \\
\text { the plant secretory pathway }\end{array}$ \\
\hline At1g65010 & 0.93 & N/A & $\begin{array}{l}\text { Encodes a microtubule-associated protein; } \\
\text { putative role in flower development }\end{array}$ \\
\hline
\end{tabular}

${ }^{\mathrm{a}} \mathrm{N} / \mathrm{A}=$ not available. At1g54030 encoding Golgi defects 36 (GOLD36) is indicated in bold. 


\section{MATERIALS AND METHODS}

Plant materials and growth conditions.

A. thaliana seeds were sown on potting mix (Pro-Mix HP, Premier Horticulture) and stratified for 5 days at $4^{\circ} \mathrm{C}$. Plants were grown in controlled-environment growth chambers (Percival Scientific) set for a 12-h photoperiod with light intensity of $120 \mu \mathrm{M}$ $\mathrm{m}^{-2} \mathrm{~s}^{-1}$ in the range of 400 to $700 \mathrm{~nm}$, constant $65 \%$ relative humidity, day temperature of $22^{\circ} \mathrm{C}$, and night temperature of $21^{\circ} \mathrm{C}$. The pen3-3 T-DNA insertion mutant (SALK_110926) (Alonso et al. 2003) and PEN3 promoter-PEN3-GFP transgenic line have been described previously (Collins et al. 2003; Stein et al. 2006). T-DNA insertion mutants mvpl-2 (SALK_030621) and ermo3-2 (SALK_135215) were acquired from the Arabidopsis Biological Resource Center (Ohio State University, Columbus, OH, U.SA.) and have also been described previously (Agee et al. 2010; Nakano et al. 2012). Both the mvpl-2 and ermo3-2 mutants have previously been shown to exhibit little or no expression of GOLD36 (Agee et al. 2010; Nakano et al. 2012).

\section{Plant transformation.}

The GOLD36-mRFP fusion, under the control of the CaMV $35 \mathrm{~S}$ promoter in plasmid pFGC5941 was provided by Dr. Federica Brandizzi (Michigan State University, East Lansing, MI, U.S.A.) and has been described previously (Marti et al. 2010). This plasmid was introduced into Agrobacterium strain GV3101 by electroporation and Arabidopsis transformation was carried out using the floral dip method (Clough and Bent 1998). Putatively transformed seeds were surface sterilized and plated

A
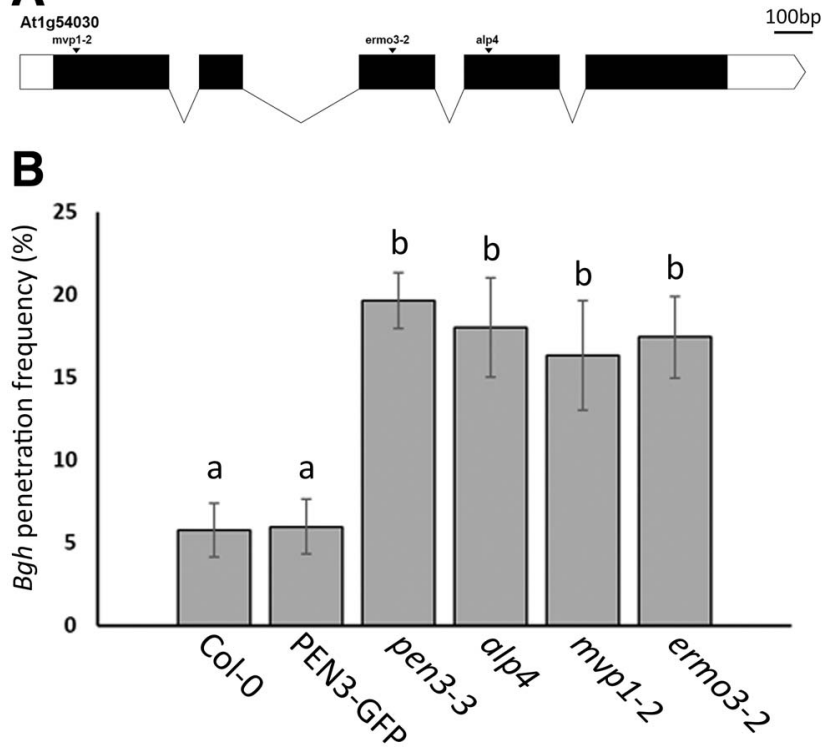

Fig. 4. Penetration defects in the aberrant localization of PEN3 4 (alp4) mutant result from mutation in GOLGI DEFECTS 36 (GOLD36). A, Schematic diagram of the Arabidopsis GOLD36 gene (At1g54030) indicating the locations of the alp 4 mutation and two previously described transferred DNA insertion mutations, mvpl-2 and ermo3-2, used in this study. White boxes indicate $5^{\prime}$ and $3^{\prime}$ untranslated regions, black boxes indicate exons, and connecting lines indicate introns. B, Blumeria graminis f. sp. hordei $(B g h)$ penetration frequencies on control, alp4, mvpl-2, and ermo3-2 plants. Penetration frequencies were determined by visually scoring for presence or absence of haustoria at 100 infection sites per leaf for three leaves per plant line at $48 \mathrm{~h}$ postinoculation. Mean values are plotted, and error bars indicate standard deviation $(n=3)$. Means indicated by the same letter are not significantly different according to analysis of variance followed by Tukey's post hoc test $(P<0.05)$. on $0.5 \times$ Murashige-Skoog medium containing $0.8 \%$ agar, $1 \%$ sucrose, and DL-phosphinothricin at $20 \mu \mathrm{g} / \mathrm{ml}$ to select for BASTA-resistant transformants. Plates were stratified at $4^{\circ} \mathrm{C}$ for 3 days, transferred to a tissue culture chamber (Percival Scientific) at $22^{\circ} \mathrm{C}$, and grown under continuous light for 14 days. T1 transformants resistant to BASTA were transplanted to potting mix and used for powdery mildew penetration assays and confocal microscopy, as described below.

\section{Powdery mildew fungal materials, inoculations, and penetration assays.}

The barley powdery mildew pathogen $B$. graminis f. sp. hordei race CR3 (Moseman 1968) was maintained as an active culture on barley variety CI-16138 (AlgerianS) (Moseman 1972). Plants were inoculated by dusting fungal conidiospores from infected barley plants over pots of Arabidopsis plants placed in a cardboard settling tower, as previously described (Zimmerli et al. 2004). Penetration frequencies were determined by removing three leaves from three different plants per genotype at $48 \mathrm{hpi}$. Excised leaves were cleared of pigment by incubating in $100 \% \mathrm{EtOH}$ at $65^{\circ} \mathrm{C}$ for $20 \mathrm{~min}$. Cleared leaves were subsequently rinsed in $\mathrm{H}_{2} \mathrm{O}$ and transferred to staining solution containing $0.01 \%$ aniline blue in $150 \mathrm{mM} \mathrm{K} \mathrm{K}_{2} \mathrm{PO}_{4}(\mathrm{pH} 9.5)$ and

\section{A}

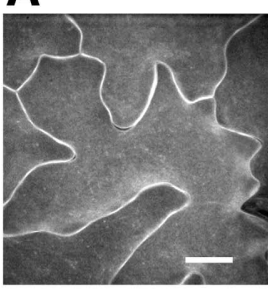

PEN3-GFP

B

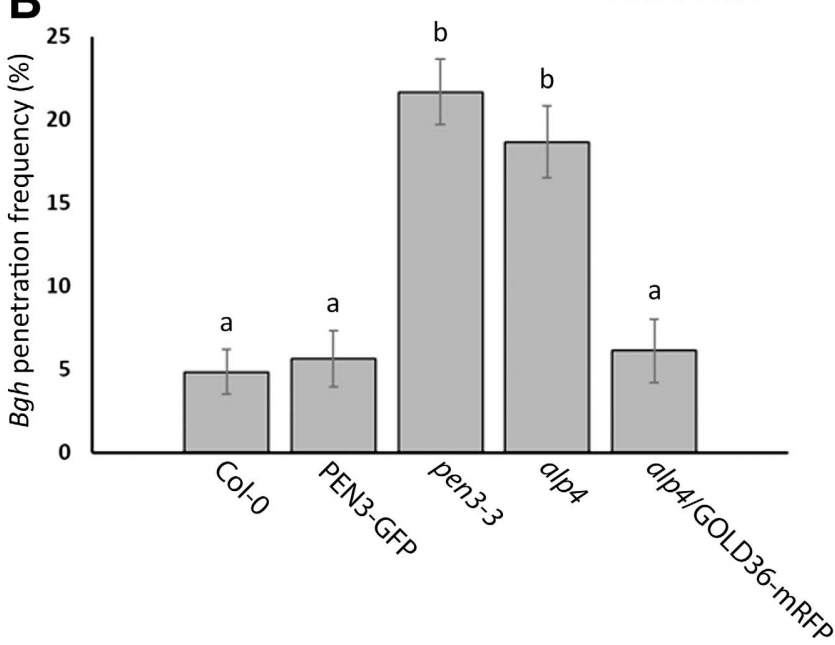

Fig. 5. Transformation with 35S::GOLGI DEFECTS 36 (GOLD36)monomeric red fluorescent protein (mRFP) rescues aberrant localization of PEN3 4 (alp4) defects in PENETRATION 3 (PEN3)-green fluorescent protein (GFP) localization and Blumeria graminis f. sp. hordei $(B g h)$ penetration defense. A, Localization of PEN3-GFP in leaf epidermal cells of the parental line (left panel), the alp4 mutant (central panel), and alp4 mutant carrying 35S::GOLD36-mRFP (right panel). Scale bars represent $20 \mu \mathrm{m}$. B, B. graminis f. sp. hordei penetration frequencies on control, alp4, and alp4/GOLD36-mRFP plants. Penetration frequencies were determined by visually scoring for presence or absence of haustoria at 100 infection sites per leaf for three leaves per plant line at $48 \mathrm{~h}$ postinoculation. Mean values are plotted, and error bars indicate standard deviation $(n=3)$. Means indicated by the same letter are not significantly different according to analysis of variance followed by Tukey's post hoc test $(P<0.05)$. 
incubated for 4 to $6 \mathrm{~h}$ at room temperature to stain the cell wall constituent callose (Vogel and Somerville 2000). Stained leaves were mounted on microscope slides in $70 \%$ glycerol and visualized using a Leica DMI $5000 \mathrm{~B}$ epifluorescence microscope using an A4 filter set (excitation filter at $365 \pm 25 \mathrm{~nm}, 400$-nm dichroic mirror, and 450-nm long-pass emission filter) and a $\times 20$ objective. Powdery mildew penetration success was evaluated by observing tips of fungal appressoria and scoring for either papillae only (small fluorescent spots stained for callose) or haustoria (large callose encasements) and papillae. Penetration frequency is determined as the number of haustoria/number of papillae expressed as a percentage (Collins et al. 2003). Mean values were compared by analysis of variance and significant differences among genotypes were determined by Tukey's post hoc test at $\alpha=0.05$.

\section{Confocal microscopy.}

Plant leaf pieces were cut from 3-week-old Arabidopsis leaves using a razor blade and mounted in $\mathrm{H}_{2} \mathrm{O}$ on microscope slides under cover glass. Mounted leaf samples were imaged using a spinning disk confocal microscope system consisting of a Leica DMI 6000 B inverted microscope (Leica Microsystems), a Yokogawa CSU-X1 spinning disk confocal unit (Yokogawa), and a Photometrics QuantEM 512SC EM-CCD camera (Photometrics). Metamorph software (Photometrics) was used for microscope system control and image acquisition. Samples were imaged using a $\times 63$ water immersion objective. The GFP fluorophore was excited using a 488-nm diode laser and emitted fluorescence was observed with an emission filter at $525 \pm 25 \mathrm{~nm}$. Plasmolysis experiments were carried out by mounting leaf samples on microscope slides in $0.85 \% \mathrm{NaCl}$ and incubating for $10 \mathrm{~min}$ at room temperature prior to imaging. Confocal $\mathrm{z}$-series were collected with a z-distance of $0.3 \mu \mathrm{m}$ and typically comprised 50 to 150 optical sections. Microscopy images were processed using ImageJ and Photoshop (Adobe). Z-projections were generated from optical sections using the maximum projection feature in ImageJ.

\section{Evaluation of PEN3-GFP extracellular accumulation.}

Plasmolysis of the PEN3-GFP parent line and the alp3 (Underwood et al. 2017) and alp4 mutants was performed as described above at 24 hpi with B. graminis f. sp. hordei. Extracellular focal accumulation of PEN3-GFP was assessed by confocal imaging and visual evaluation of PEN3-GFP accumulation at tips of B. graminis f. sp. hordei haustoria outside the boundaries of retracted protoplasts. For each genotype, PEN3-GFP accumulation was scored at 25 penetration sites in each experimental replication and three total replications were performed. The percentage of PEN3-GFP extracellular focal accumulation was determined by dividing the number of sites with observable PEN3-GFP extracellular accumulation by the total number of sites scored, and the data from three experimental replications were combined for analysis. Mean values were compared by analysis of variance and significant differences among genotypes were determined by Tukey's post hoc test at $\alpha=0.05$.

\section{Genetic mapping of alp4.}

A mapping population was developed by crossing alp4, an ethyl methanesulfonate (EMS)-generated mutant in the Col-0 genetic background, with the Ler ecotype. $F_{2}$ individuals were evaluated by confocal microscopy to identity segregants exhibiting the alp4 phenotype of PEN3-GFP accumulation within an ER-like endomembrane compartment with abnormal morphology. Leaf tissues from a total of $50 \mathrm{~F}_{2}$ individuals exhibiting the alp4 phenotype were bulked and the bulked tissue was subjected to genomic DNA isolation using a Puregene DNA isolation kit according to the manufacturer's instructions (Qiagen). In total, $50 \mathrm{ng}$ of genomic DNA from bulked segregant tissue was used to prepare a library for Illumina sequencing. Library preparation was carried out using the Illumina Nextera DNA library preparation kit according to the manufacturer's instructions (Illumina). The prepared library was evaluated on a Bioanalyzer (Agilent) to assess fragment size distribution and DNA quantity was assessed using a Quant-iT PicoGreen dsDNA assay kit (Invitrogen). The library was then sequenced on a single lane of an Illumina HiSeq 2000 instrument. Sequence reads were aligned to the TAIR 10 Arabidopsis Col-0 reference genome assembly using the Bowtie aligner (Langmead et al. 2009) and variant calling was carried out using SAMtools ( $\mathrm{Li}$ et al. 2009). Singlenucleotide polymorphism (SNP) variants were subsequently used in the Next Generation Mapping procedure as previously described (Austin et al. 2011) using a web-based mapping tool (NGM website). Genes carrying SNPs consistent with the G/C to $\mathrm{A} / \mathrm{T}$ transitions commonly observed for EMS mutagenesis, located within the mapped region on chromosome 1 and exhibiting a discordant chastity value of $\geq 0.9$, were regarded as candidate genes.

\section{ACKNOWLEDGMENTS}

This work was initiated as a forward genetic screen carried out in the laboratory of S. Somerville at University of California, Berkeley and I am grateful to Dr. Somerville for initial support of the project. I also thank J. Wei for technical assistance, M. Chung for guidance on Illumina library preparation, and F. Brandizzi for kindly sharing the GOLD36-mRFP plasmid.

\section{AUTHOR-RECOMMENDED INTERNET RESOURCE}

NGM-Next-Generation EMS mutation mapping: http://bar.utoronto.ca/ngm

\section{LITERATURE CITED}

Agee, A. E., Surpin, M., Sohn, E. J., Girke, T., Rosado, A., Kram, B. W., Carter, C., Wentzell, A. M., Kliebenstein, D. J., Jin, H. C., Park, O. K., Jin, H., Hicks, G. R., and Raikhel, N. V. 2010. MODIFIED VACUOLE PHENOTYPE1 is an Arabidopsis myrosinase-associated protein involved in endomembrane protein trafficking. Plant Physiol. 152:120-132.

Alonso, J. M., Stepanova, A. N., Leisse, T. J., Kim, C. J., Chen, H., Shinn, P., Stevenson, D. K., Zimmerman, J., Barajas, P., Cheuk, R., Gadrinab, C., Heller, C., Jeske, A., Koesema, E., Meyers, C. C., Parker, H., Prednis, L., Ansari, Y., Choy, N., Deen, H., Geralt, M., Hazari, N., Hom, E., Karnes, M., Mulholland, C., Ndubaku, R., Schmidt, I., Guzman, P., Aguilar-Henonin, L., Schmid, M., Weigel, D., Carter, D. E., Marchand, T., Risseeuw, E., Brogden, D., Zeko, A., Crosby, W. L., Berry, C. C., and Ecker, J. R. 2003. Genomewide insertional mutagenesis of Arabidopsis thaliana. Science 301: 653-657.

Assaad, F. F., Qiu, J. L., Youngs, H., Ehrhardt, D., Zimmerli, L., Kalde, M., Wanner, G., Peck, S. C., Edwards, H., Ramonell, K., Somerville, C. R., and Thordal-Christensen, H. 2004. The PEN1 syntaxin defines a novel cellular compartment upon fungal attack and is required for the timely assembly of papillae. Mol. Biol. Cell 15:5118-5129.

Austin, R. S., Vidaurre, D., Stamatiou, G., Breit, R., Provart, N. J., Bonetta, D., Zhang, J., Fung, P., Gong, Y., Wang, P. W., McCourt, P. and Guttman, D. S. 2011. Next-generation mapping of Arabidopsis genes. Plant J. 67:715-725.

Barnes, E. H. 1979. The powdery mildews. Pages 167-175 in: Atlas and Manual of Plant Pathology. E. H. Barnes, ed. Plenum Press, New York, NY, U.S.A.

Beck, M., Zhou, J., Faulkner, C., MacLean, D., and Robatzek, S. 2012. Spatio-temporal cellular dynamics of the Arabidopsis flagellin receptor reveal activation status-dependent endosomal sorting. Plant Cell 24: 4205-4219.

Bednarek, P., Pislewska-Bednarek, M., Svatos, A., Schneider, B., Doubsky, J., Mansurova, M., Humphry, M., Consonni, C., Panstruga, R., Sanchez-Vallet, A., Molina, A., and Schulze-Lefert, P. 2009. A glucosinolate metabolism pathway in living plant cells mediates broad-spectrum antifungal defense. Science 323:101-106.

Bhandari, D. D., and Brandizzi, F. 2020. Plant endomembranes and cytoskeleton: Moving targets in immunity. Curr. Opin. Plant Biol. 58:8-16. 
Cai, Q., Qiao, L., Wang, M., He, B., Lin, F. M., Palmquist, J., Huang, S. D., and Jin, H. 2018. Plants send small RNAs in extracellular vesicles to fungal pathogen to silence virulence genes. Science 360:1126-1129.

Clay, N. K., Adio, A. M., Denoux, C., Jander, G., and Ausubel, F. M. 2009. Glucosinolate metabolites required for an Arabidopsis innate immune response. Science 323:95-101.

Clough, S. J., and Bent, A. F. 1998. Floral dip: A simplified method for Agrobacterium-mediated transformation of Arabidopsis thaliana. Plant J. 16:735-743.

Collins, C. A., LaMontagne, E. D., Anderson, J. C., Ekanayake, G., Clarke, A. S., Bond, L. N., Salamango, D. J., Cornish, P. V., Peck, S. C., and Heese, A. 2020. EPSIN1 modulates the plasma membrane abundance of FLAGELLIN SENSING2 for effective immune responses. Plant Physiol. 182:1762-1775.

Collins, N. C., Thordal-Christensen, H., Lipka, V., Bau, S., Kombrink, E., Qiu, J. L., Hückelhoven, R., Stein, M., Freialdenhoven, A., Somerville, S. C., and Schulze-Lefert, P. 2003. SNARE-protein-mediated disease resistance at the plant cell wall. Nature 425:973-977.

Du, Y., Mpina, M. H., Birch, P. R., Bouwmeester, K., and Govers, F. 2015. Phytophthora infestans RXLR Effector AVR1 interacts with exocyst component Sec5 to manipulate plant immunity. Plant Physiol. 169:1975-1990.

Ellinger, D., Naumann, M., Falter, C., Zwikowics, C., Jamrow, T., Manisseri, C., Somerville, S. C., and Voigt, C. A. 2013. Elevated early callose deposition results in complete penetration resistance to powdery mildew in Arabidopsis. Plant Physiol. 161:1433-1444.

Fuchs, R., Kopischke, M., Klapprodt, C., Hause, G., Meyer, A. J. Schwarzländer, M., Fricker, M. D., and Lipka, V. 2016. Immobilized subpopulations of leaf epidermal mitochondria mediate PENETRATION2dependent pathogen entry control in Arabidopsis. Plant Cell 28:130-145.

Glawe, D. A. 2008. The powdery mildews: A review of the world's most familiar (yet poorly known) plant pathogens. Annu. Rev. Phytopathol. 46:27-51.

He, Y., Xu, J., Wang, X., He, X., Wang, Y., Zhou, J., Zhang, S., and Meng, X. 2019. The Arabidopsis pleiotropic drug resistance transporters PEN3 and PDR12 mediate camalexin secretion for resistance to Botrytis cinerea. Plant Cell 31:2206-2222.

Hématy, K., Lim, M., Cherk, C., Piślewska-Bednarek, M., SanchezRodriguez, C., Stein, M., Fuchs, R., Klapprodt, C., Lipka, V., Molina, A., Grill, E., Schulze-Lefert, P., Bednarek, P., and Somerville, S. 2020. Moonlighting function of phytochelatin synthase1 in extracellular defense against fungal pathogens. Plant Physiol. 182:1920-1932.

Hossain, M. M., Pérez-López, E., Todd, C. D., Wei, Y., and BonhamSmith, P. C. 2021. Endomembrane-targeting Plasmodiophora brassicae effectors modulate PAMP triggered immune responses in plants. Front. Microbiol. 12:651279.

Jacobs, A. K., Lipka, V., Burton, R. A., Panstruga, R., Strizhov, N., Schulze-Lefert, P., and Fincher, G. B. 2003. An Arabidopsis Callose Synthase, GSL5, Is Required for Wound and Papillary Callose Formation. Plant Cell 15:2503-2513.

Jancowski, S., Catching, A., Pighin, J., Kudo, T., Foissner, I., and Wasteneys, G. O. 2014. Trafficking of the myrosinase-associated protein GLL23 requires NUC/MVP1/GOLD36/ERMO3 and the p24 protein CYB. Plant J. 77:497-510.

Langmead, B., Trapnell, C., Pop, M., and Salzberg, S. L. 2009. Ultrafast and memory-efficient alignment of short DNA sequences to the human genome. Genome Biol. 10:R25.

Lee, A. H., Hurley, B., Felsensteiner, C., Yea, C., Ckurshumova, W., Bartetzko, V., Wang, P. W., Quach, V., Lewis, J. D., Liu, Y. C., Börnke, F., Angers, S., Wilde, A., Guttman, D. S., and Desveaux, D. 2012. A bacterial acetyltransferase destroys plant microtubule networks and blocks secretion. PLoS Pathog. 8:e1002523.

Li, H., Handsaker, B., Wysoker, A., Fennell, T., Ruan, J., Homer, N., Marth, G., Abecasis, G., Durbin, R., and 1000 Genome Project Data Processing Subgroup. 2009. The Sequence Alignment/Map format and SAMtools. Bioinformatics 25:2078-2079.

Lipka, V., Dittgen, J., Bednarek, P., Bhat, R., Wiermer, M., Stein, M., Landtag, J., Brandt, W., Rosahl, S., Scheel, D., Llorente, F., Molina, A., Parker, J., Somerville, S., and Schulze-Lefert, P. 2005. Pre- and postinvasion defenses both contribute to nonhost resistance in Arabidopsis. Science 310:1180-1183.

Mao, H., Aryal, B., Langenecker, T., Hagmann, J., Geisler, M., and Grebe, M. 2017. Arabidopsis BTB/POZ protein-dependent PENETRATION3 trafficking and disease susceptibility. Nat. Plants 3:854-858.
Marti, L., Stefano, G., Tamura, K., Hawes, C., Renna, L., Held, M. A. and Brandizzi, F. 2010. A missense mutation in the vacuolar protein GOLD36 causes organizational defects in the ER and aberrant protein trafficking in the plant secretory pathway. Plant J. 63:901-913.

Matern, A., Böttcher, C., Eschen-Lippold, L., Westermann, B., Smolka, U., Döll, S., Trempel, F., Aryal, B., Scheel, D., Geisler, M., and Rosahl, S. 2019. A substrate of the ABC transporter PEN3 stimulates bacterial flagellin (flg22)-induced callose deposition in Arabidopsis thaliana. J. Biol. Chem. 294:6857-6870.

Mbengue, M., Bourdais, G., Gervasi, F., Beck, M., Zhou, J., Spallek, T., Bartels, S., Boller, T., Ueda, T., Kuhn, H., and Robatzek, S. 2016. Clathrin-dependent endocytosis is required for immunity mediated by pattern recognition receptor kinases. Proc. Natl. Acad. Sci. U.S.A. 113:11034-11039.

Meyer, D., Pajonk, S., Micali, C., O'Connell, R., and Schulze-Lefert, P. 2009. Extracellular transport and integration of plant secretory proteins into pathogen-induced cell wall compartments. Plant J. 57:986-999.

Moseman, J. G. 1968. Reactions of barley to Erysiphe graminis f. sp. hordei from North America. Plant Dis. Rep. 52:463-467.

Moseman, J. G. 1972. Isogenic barley lines for reaction to Erysiphe graminis f. sp. hordei. Crop Sci. 12:681-682.

Nakano, R. T., Matsushima, R., Nagano, A. J., Fukao, Y., Fujiwara, M., Kondo, M., Nishimura, M., and Hara-Nishimura, I. 2012. ERMO3/ MVP1/GOLD36 is involved in a cell type-specific mechanism for maintaining ER morphology in Arabidopsis thaliana. PLoS One 7: e49103.

Nishimura, M. T., Stein, M., Hou, B. H., Vogel, J. P., Edwards, H., and Somerville, S. C. 2003. Loss of a callose synthase results in salicylic acid-dependent disease resistance. Science 301:969-972.

Nomura, K., Mecey, C., Lee, Y. N., Imboden, L. A., Chang, J. H., and He, S. Y. 2011. Effector-triggered immunity blocks pathogen degradation of an immunity-associated vesicle traffic regulator in Arabidopsis. Proc. Natl. Acad. Sci. U.S.A. 108:10774-10779.

Ortiz-Morea, F. A., Savatin, D. V., Dejonghe, W., Kumar, R., Luo, Y., Adamowski, M., Van den Begin, J., Dressano, K., Pereira de Oliveira, G., Zhao, X., Lu, Q., Madder, A., Friml, J., Scherer de Moura, D., and Russinova, E. 2016. Danger-associated peptide signaling in Arabidopsis requires clathrin. Proc. Natl. Acad. Sci. U.S.A. 113:11028-11033.

Rutter, B. D., and Innes, R. W. 2017. Extracellular vesicles isolated from the leaf apoplast carry stress-response proteins. Plant Physiol. 173: 728-741.

Rutter, B. D., and Innes, R. W. 2018. Extracellular vesicles as key mediators of plant-microbe interactions. Curr. Opin. Plant Biol. 44:16-22.

Sassmann, S., Rodrigues, C., Milne, S. W., Nenninger, A., Allwood, E., Littlejohn, G. R., Talbot, N. J., Soeller, C., Davies, B., Hussey, P. J., and Deeks, M. J. 2018. An immune-responsive cytoskeletal-plasma membrane feedback loop in plants. Curr. Biol. 28:2136-2144.e7.

Stein, M., Dittgen, J., Sánchez-Rodríguez, C., Hou, B. H., Molina, A., Schulze-Lefert, P., Lipka, V., and Somerville, S. 2006. Arabidopsis PEN3/PDR8, an ATP binding cassette transporter, contributes to nonhost resistance to inappropriate pathogens that enter by direct penetration. Plant Cell 18:731-746.

Underwood, W., Ryan, A., and Somerville, S. C. 2017. An Arabidopsis lipid flippase is required for timely recruitment of defenses to the host-pathogen interface at the plant cell surface. Mol. Plant 10:805820.

Underwood, W., and Somerville, S. C. 2008. Focal accumulation of defences at sites of fungal pathogen attack. J. Exp. Bot. 59:3501-3508.

Underwood, W., and Somerville, S. C. 2013. Perception of conserved pathogen elicitors at the plasma membrane leads to relocalization of the Arabidopsis PEN3 transporter. Proc. Natl. Acad. Sci. U.S.A. 110: 12492-12497.

Vogel, J., and Somerville, S. 2000. Isolation and characterization of powdery mildew-resistant Arabidopsis mutants. Proc. Natl. Acad. Sci. U.S.A. 97:1897-1902.

Wu, G., Liu, S., Zhao, Y., Wang, W., Kong, Z., and Tang, D. 2015. ENHANCED DISEASE RESISTANCE4 associates with CLATHRIN HEAVY CHAIN2 and modulates plant immunity by regulating relocation of EDR1 in Arabidopsis. Plant Cell 27:857-873.

Zimmerli, L., Stein, M., Lipka, V., Schulze-Lefert, P., and Somerville, S. 2004. Host and non-host pathogens elicit different jasmonate/ethylene responses in Arabidopsis. Plant J. 40:633-646. 